\title{
COMUNICACIÓN INTERNA Y FUSIÓN DE EMPRESAS: LA NECESIDAD DE UNA PLANIFICACIÓN
}

\author{
Anabela Ferreira Félix-Mateus¹: Universidade de Trás-os-Montes e Alto-Douro. \\ Portugal \\ anabela.mateus@netcabo.pt
}

\section{RESUMEN}

Basándonos en el conocimiento empírico de algunas consecuencias nefastas derivadas de la revolución del 25 de Abril de 1974 en Portugal, intentamos analizar los resultados de las fusiones a nivel de comunicación interna y del conjunto del clima interno que se generó con los cambios provocados con las fusiones empresariales de 1980, muy relevantes en el ámbito de la actividad aseguradora en mi País. Recurrimos para ello a una metodología de base cualitativa con entrevistas abiertas, semiestructuradas, y realizamos un estudio comparado entre dos grupos de empresas sometidas a dichos procesos de fusión. El factor principal que distingue a los grupos analizados se sitúa a nivel de los momentos de cambio; así, mientras que en un grupo el proceso es inmediato, instantáneo, en el otro se revela longitudinal, por fases planeado a lo largo de tres años, lo que posibilitó la preparación para el cambio que se avecinaba. En términos de resultados obtenidos, hemos de admitir que la confusión inicialmente percibida en los procesos de fusión, se verifica principalmente en la nueva empresa que no lleva a cabo ningún tipo de preparación en su nueva constitución, mientras que el mismo proceso resulta mucho más sencillo en la que sí tuvo la oportunidad de hacer planes durante los tres años de adaptación

PALABRAS CLAVE: Comunicación interna - clima organizacional - cultura de empresa - proceso de fusión - cambio

\footnotetext{
${ }^{1}$ Autor correspondiente

Anabela Ferreira Félix-Mateus: Investigadora FCT- Fundação para a Ciência e Tecnologia. Universidade de Trás-os-Montes e Alto-Douro, Portugal

Correo: anabela.mateus@netcabo.pt
} 


\title{
INTERNAL COMMUNICATIÓN AND MERGER OF COMPANIES THE NEED OF A PLANNING
}

\begin{abstract}
Working from the empiric knowledge of some critical consequences resulting from 25th April 1974 Revolution in Portugal, we tried to analyse the results from fusions in internal communication and the internal climate originated by the changes occurred in 1980 company mergers, very significant in the realm of the insurance activity of the Country. We supported our study with a qualitative methodology led through open semi- structured interviews, as well as a comparative study among two groups of companies under such fusion processes. The key factor that distinguishes the two studied groups is set at the level of moments of change; therefore, while in one group the process is immediate, instantaneous, in the other it is longitudinal, in stages, planed through three years, which enabled the preparation for change that would come along In terms of achieved results, we have to admit that the confusion initially perceived in the fusion processes is registered mainly in the new companies that do not conduct any type of preparation in its new constitution, while the process is far easier in the ones that had the opportunity to plan during the three year adaptation period.
\end{abstract}

KEY WORDS: Internal communication - organizational climate - company culture fusion process - change

\section{COMUNICAÇÃO INTERNA E FUSÃO DE EMPRESAS: A NECESSIDADE DE UM PLANEAMENTO}

\section{RESUMO}

Baseando-nos em conhecimento empírico de algumas consequências nefastas derivadas da Revolução do 25 de Abril de 1974 em Portugal, tentamos analisar os resultados das fusões a nível da comunicação interna e do conjunto do clima interno que se gerou com as mudanças provocadas com as fusões empresariais de 1980, muito relevantes no âmbito da actividade seguradora no País. Recorremos a metodologia de base qualitativa com entrevistas abertas, semi-estruturadas, e realizamos um estudo comparado entre dois grupos de empresas submetidas a tais processos de fusão. O factor principal que distingue os grupos analisados situa-se a nível dos momentos da mudança; assim, enquanto que num grupo o processo é imediato, instantâneo, no outro revela-se longitudinal, por fases, planeado ao longo de três anos, o que possibilitou a preparação para a mudança que se avizinhava. Em termos de resultados obtidos, temos que admitir que a confusão inicialmente percebida nos processos de fusão, se verifica principalmente na nova empresa que não leva a cabo nenhum tipo de preparação na sua nova constituição, enquanto que o mesmo processo 
resulta muito mais facilitado naquela que teve oportunidade de fazer planos durante os três anos de adaptação.

PALAVRAS-CHAVE: Comunicação interna - clima organizacional - cultura de empresa - processo de fusão - mudança

\section{INTRODUÇÃO}

Com a nova economia e a globalização surge uma nova realidade. Cada vez mais há menos "espaço" para os mais pequenos, para os menos poderosos. Aquisições e fusões são cada vez mais constantes para que as empresas possam encarar as características da globalização, recorrente da nova economia e da abertura de fronteiras a nível económico.

O presente artigo resulta da investigação levada a cabo para obtenção do grau de doutor em Ciências da Informação pela autora, na Universidade Complutense de Madrid.

O objeto da nossa curiosidade científica que incidiu nas consequências a nível da comunicação interna em empresas de actividade seguradora, das mais representativas enquanto alvo de fusão, teve como fim apurar os resultados em termos humanos e sociais desse processo de mudança.

Não se trata de uma preocupação actual e por conseguinte já pensada à luz de perspectivas sociológicas, de relações humanas e, mais recentemente, de comunicação empresarial.

O trabalho de investigação que nos permitiu o estudo de uma realidade de há duas décadas, e principalmente as suas consequências, pode parecer ultrapassado no tempo, desactualizado, fora de época, enfim sem utilidade científica prática. Não é essa a presente perspectiva. Fusões e aquisições são estratégias a que cada vez mais assistimos em consequência da realidade da globalização.

Em simultâneo, a conjuntura em Portugal de crise económica encontra em situações de união empresarial uma oportunidade para empresas de pequeno porte. A abertura de fronteiras permite uma internacionalização crescente a que obriga uma união de esforços das empresas nacionais para uma concorrência directa. Hoje elas já não conseguem viver isoladas umas das outras, com pequena dimensão, sob pena de serem aglutinadas

Se bem que a nível de empresas com a dimensão das seguradoras, e outras paralelas, as fusões e aquisições tenham conhecimentos para assumir, já hoje em dia, capacidades que ultrapassam, em nosso entender, os graves problemas das transformações internas ocorridas no início dos anos oitenta, temos que aceitar que empresas mais peauenas, de médio e mesmo pequeno potentado económico, têm a 
necessidade de se unir para poderem continuar activas no presente mercado; as suas estruturas internas encontram-se cada vez mais abaláveis.

Cada vez mais é necessária a conjugação de esforços num mundo que se encontra por um lado mais próximo pelo efeito da globalização e também mais impessoal pela introdução de novas tecnologias, pelo aumento da dimensão das empresas que necessariamente vêm tornar a comunicação mais abstracta, virtual, funcionando através de processos se bem mais rápidos, mais despersonalizados e impessoais, e, por isso mesmo, com maior probabilidade de ineficácia, se encarados numa perspectiva do ser social.

No âmbito dos nossos propósitos apresentou-se-nos fundamental, numa primeira fase, caracterizar o funcionamento das empresas objecto de estudo a nível de recursos humanos e sua comunicação interna interactiva, nos momentos ante e pós- fusão, para, de seguida, podermos analisar o resultado das reestruturações em termos de equilíbrio do clima e coesão da cultura, e a participação efectiva da comunicação para a eficácia nessa mudança.

\subsection{Referenciais Teóricos}

À luz da reflexão científica existente inspirámo-nos numa "abordagem analítica de base sistémica". Segundo esta abordagem a comunicação é perspectivada como um sistema e adquire prioridade perante o sujeito integrado nela. Este é um ponto que se apresenta comum a todos os teóricos que perfilham a perspectiva. $\mathrm{O}$ autor cujos estudos se encontram mais relacionados com o nosso tema é Goffman (Cooley, cit. por Nguyen-Thanh in Almeida, 2000). Dentro das suas preocupações tentou definir uma "teoría sociológica da comunicação interpessoal", que apresentou como tema central da sua tese de Doutoramento.

Baseando-nos na perspectiva sistémica, "consideramos a própria organização como um sistema e, desta forma, pode ser definida como um conjunto de elementos dinamicamente interrelacionados que desenvolvem uma actividade comum para alcançar determinados objectivos" (Teixeira, 1998, p. 22). Neste âmbito, a comunicação é encarada no seio das organizações por vários autores como o mecanismo pelo qual existem e se desenvolvem as relações humanas. Segundo eles, ela traduz-se através da comunicação "intrapessoal, interpessoal, intraorganizacional e extraorganizacional" (Cooley, cit. por Nguyen-Thanh, p. 24, in Almeida, 2000 pp.19/20). Perspectiva sistémica esta que já contempla as relações humanas a vários níveis organizacionais. E não só internamente. Também já aquí o fator externo é contemplado - a empresa é vista no seu meio ambiente, o que nos abre campo teórico à nossa perspectiva, e, concretamente à problemática que aqui analisamos:

...com o surgimento da teoria geral dos sistemas, o ambiente externo adquire uma nova dimensão no estudo do comportamento organizacional e da comunicação organizacional. Exemplos de estudos de comunicação nesta área 
incluem a análise do clima e da cultura organizacional e a actividade de relações públicas na criação da identidade da organização e das suas fronteiras." (Jablin et al, in Ferreira et al, 1996, p. 179)

Também Sanz de la Tajada (in Martins, 2004, p. 99), na linha da nossa investigação, vem enriquecer esta perspectiva com a relação entre a cultura, a integração doscolaboradores e a imagem interna da empresa. Mas vários outros contributos fazem parte do quadro conceptual da presente investigação. Muitos aspectos se interligam. É a perspectiva sistémica que também aqui se impõe.

Tendo como cerne da pesquisa realizada os conceitos Fusão empresarial, Cultura de Empresa e Clima Organizacional, que consideramos o núcleo da mesma dado que à sua volta se encontra relacionada toda a problemática com o tema em questão - a Comunicação Interna-, outros conceitos no campo sociológico e até psicológico se entrecruzam neste âmbito. Desde já os conceitos de Anomia, Entropia e Segurança Ontológica, no caso a falta dela. Estados que se vieram a verificar em consequência dos processos operados. Reacções do foro emocional que demonstram confusão, distúrbios, instabilidade, insegurança e consequente falta de integração na nova situação. Segundo Lakatos (1987, pp. 318/319): “... a desorganização pessoal, por sua vez, vê-se como um reflexo da desorganização social".

Numa outra perspectiva, não podemos deixar de atribuir lugar de relevo a aspectos como a Motivação, a Satisfação no trabalho, a Participação no âmbito da organização e da mudança. Nesta relação está confirmado que a participação activa dos trabalhadores leva à satisfação de um conjunto de necessidades individuais e engloba um conjunto de motivações básicas. Traduz a forma de reconhecimento e contribui para a satisfação das necessidades de afiliação e aceitação por parte dos outros, assim como a necessidade de realização; encontra-se na base de gestão por objectivos uma vez que contribui para o aproveitamento dos conhecimentos dos trabalhadores na tomada de decisões na empresa (Teixeira, 1998, p. 135). São abordagens que sentimos necessidade de introduzir pela relevância das emoções e situações traduzidas em campo, fruto da realidade que foi a fusão.

O conceito de estratégia dos actores surge no âmbito da corrente Análise Estratégica apresentada nos anos 70 por Michel Crozier e Erhard Friedberg no livro L'Acteur et le Système. Foram os primeiros a propôr o estudo da organização como um fenómeno autónomo e não determinado por condicionantes externas, como nos apresentou Bernoux (1989, p.117). Vêm defender que os homens têm estratégias pessoais de actuação dentro da organização para atingirem os seus objectivos, individualmente ou em grupo, distintos dos objectivos da organização formal, que se vão traduzir aí em jogos de poder e que se contrapõem ao poder formal, tradicionalmente instituído. São estes, aspectos informais dentro da organização, a preocupação central da abordagem. Encontra-se assim uma organização formal e uma organização informal onde os actores assumem funções ou papeis, consoante as distintas situações. 
A participação, a que já nos referimos em relação aos conceitos de motivação e satisfação, só se vai começar a traduzir efectivamente em estruturas participativas com o surgimento da corrente da Cultura de Empresa, ainda que anteriormente já se tivesse vislumbrado um prenúncio desta teoría junto das filosofías da motivação, como vimos, que se podem considerar originárias dos anos 30, ou em correntes organizacionais como a Análise Estratégica.

Nos finais dos anos 70, década de 80, o homem passa a ter, na realidade, cada vez mais possibilidade de se manifestar a respeito do seu trabalho e da organização, relativamente à concepção, acção e reflexão, num todo global, e isto não deixa de ser inovador porque, antes disso, quando existía essa liberdade, traduzia-se em posições tomadas individualmente. Como não pode deixar de acontecer, os sistemas de informação e de comunição começam a ganhar cada vez mais importância. O conceito de qualidade de vida no trabalho surge em consonância.

O conceito de Cultura de Empresa, por sua vez, aparece para explicar a longevidade e vitalidade de determinadas empresas que encontram em si próprias, e não em modelos alheios, o seu êxito. E, segundo a moda da época, representada por Ouchi, autor da Teoria Z (Ouchi, 1985, cit. por Teixeira, 1988, p.136) constitui a afirmação do direito à diferença. Sem dúvida, não podemos esquecer a pouca aplicabilidade que resultou da teoría, precisamente pela diferença das culturas em que foi criada e transposta, do Japão para os EUA.

Também se encontrará na base das teorías da OD (Desenvolvimento Organizacional) que preconizou diversos métodos de evolução programada das organizações e do seu funcionamento (Thévenet 1990, p. 18) Não se pode deixar de considerar como marco a obra de principios dos anos 80, famosa em todo o mundo, In Search of Excellence. Publicada nos EUA em 1980, em França em 1985 e em Portugal em 1987, o livro, que reflecte essa corrente, acaba, sem dúvida, por não passar de principios teóricos, que viríam a saber-se construídos sob dados viciados, segundo a confissão dos próprios autores (Cunha et al, 2003, p. 528). Não deixou, apesar disso, de alertar para a problemática em questão. $\mathrm{Na}$ realidade, tanto a teoría $\mathrm{Z}$ como a $\mathrm{OD}$ e a corrente da Excelência revelaram que "a cultura é uma noção pertinente na medida em que permite compreender o funcionamento das organizações e resolver os seus problemas" e que ela é "o factor de êxito qundo é forte, quer dizer, quando modela os comportamentos e as formas de gestão" (Thévenet, 1986, p. 18). Mas apenas isso.

Na mesma linha Schein vai ainda mais longe. No seu livro Organizational Culture and Leadership, que publicou em 1985, apresentou un conceito globalizante: o de Gestão pela Cultura.

A corrente da Cultura de Empresa surge, então, quase simultaneamente, em finais da década de 70, principios de 80, sob duas perspectivas diferentes mas complementares, em França e nos EUA. 
O conceito de Identidade, pela mão do francês Renaud Sainsaulieu (1977) é essencial para entender a sua posição, tal como o de Gestão pela Cultura o é para o Norte Americano Edgar Schein Nos anos 70 fazia-se apología das PME (Small is beautifull - Schumacher, 1978, in Lopes and Reto, 1990, p.16). Passados 10 anos, as novas formas de gestão e a globalização da economia em conjunto com as novas tecnologías, entre outros factores, levam a reinar as grandes organizações, a criação de uma sociedade de macroorganizações flexiveis que actuam à escala mundial ${ }^{2}$. Um dos autores que se preocuparia com esse aspecto, precisamente na perspectiva francesa da cultura de empresa, foi Sainsaulieu. Há que salientar a influência que Crozier e a sua teoría da Análise Estratégica tiveram sobre este autor, assim como sobre Bernoux. Segundo Bernoux (1985), a explosão da corrente está relacionada com a multipicação das fusões e das dificuldades com elas relacionadas. Por seu lado, este autor segue de perto a perspectiva de Sainsaulieu. Em função de toda a nossa investigação esta é uma posição que não podemos deixar de considerar, uma vez que o conceito de Cultura de Empresa, indubitavelmente fundamental nos processos de fusão, encontra aqui um excelente campo de fundamentação. Segundo Bernoux (1985, p.191): “...se duas empresas fabricam num mesmo país um produto idêntico num mercado muito competitivo, e se reconhecem as dificuldades e/ou perdas financeiras, a lógica implica que elas tentem aproximar-se, podendo ou não chegar à fusão."

O conceito Clima Organizacional surge relacionado com aspectos psicológicos, de tal forma que foi introduzido na literatura organizacional por psicólogos. Mais tarde Goleman (2000, in Cunha et al., 2003), vai apresentar um conjunto de factores que influenciam o ambiente de trabalho, como flexibilidade, responsabilidade, modelos, recompensas, clareza e empenho, e sugerir uma relação com os estilos de liderança.

A Mudança caracteriza uma fusão. Todas as empresas devem adaptar-se permanentemente às evoluções do ambiente, se se quiserem manter ou desenvolver. A Mudança na organização, e principalmente em situações como as da presente investigação, deverá prever uma mudança de cultura, simultânea, adaptada à nova organização. A Mudança não é um fim em si mesmo, mas uma necessidade para fazer um sistema passar de um estado a outro. Tem lugar sempre que se modifica um objectivo, uma norma, uma regra, um comportamento repetitivo ou um processo de transformação (Bériot, 1997, p. 97).

O Desenvolvimento Organizacional (OD) surge como uma abordagem subjacente à mudança nas organizações, mas uma mudança em termos de evolução programada do seu funcionamento.

A oportunidade da introdução destes conceitos surge porque entendemos que qualquer processo de fusão deve ser acompanhado por uma estratégia de mudança

\footnotetext{
2 Não é demais recordar que 85\% das PME's dos anos 70 fusionaram-se ou foram absorvidas por grandes empresas, como demonstram estudos realizados.

3 trad noconal
} 
realmente programada, com base em técnicas de denvolvimento organizacional, já testadas.

O papel da liderança e dos líders, como elementos orientadores de todo o processo, não deixa de ser fundamental para a integração dos outros membros, pelo que também lhe dedicamos uma referência, alulindo à postura de Schein e de Thévenet.

Para encerrar o círculo, o conceito básico à preocupação que nos conduz: fusão empresarial. De carácter pragmático, fundamental a sua definição no presente contexto. Demasiado longas as caracterizações existentes que serviram de base à nossa investigação. Ficamo-nos pela sua referência

\section{METODOLOGÍA}

A definição conceptual do nosso Objetivo de Investigação situa-se ao nivel da Comunicação Interna enquanto Estratégia de Gestão no âmbito da empresa.

O papel da comunicação interna em situações de mudança, representadas aquí pelos processos de fusão empresarial em empresas seguradoras, a nivel da estabilidade do clima interno e da coesão da cultura da empresa, tornou-se a nossa meta de investigação.

O que nos propusemos inicialmente encontrar com a investigação projetada era resposta à seguinte questão - Pergunta de investigação: “Até que ponto a comunicação empresarial em processos de mudança - no presente caso as fusões empresariais - poderá contribuir para a estabilização do clima empresarial e/ou para a coesão da cultura da empresa?"

Para a definição das unidades de investigação fizemos um Estudo Exploratório antecipado, com base em Análise documental e Conversas informais a Informadores qualificados, com vista ao conhecimento mais profundo do Campo de Observação, da actividade em causa e da sua evolução, e à opção definitiva do Objecto de estudo - as empresas a investigar entre a oferta existente.

Com os resultados obtidos com o Estudo Exploratório definimos a estratégia metodológica de investigação e as técnicas a ela intrínsecas. De imediato verificámos limitações insuperáveis na utilização de qualquer técnica de tipo Quantitativo, pela dispersão espacial dos informadores, consequência do desfasamento temporal em relação às datas das fusões. Sem perder de vista o objeto de estudo - a compreensão da mudança operada - tornou-se necessário dividir a investigação em duas fases distintas: antes e depois da fusão formalizada e generalizada das empresas seguradoras. Isto tendo em vista o objetivo final que é tentar entender junto dos individuos afetados com o proceso de fusão as perceções e os sentimentos por eles experimentados nos dois momentos.

As grandes Dimensões de Análise do tema, cujo objetivo é um maior aprofundamento desses níveis, ressaltaram igualmente desta investigação primária, já que são elas que fundamentam o "Guião da Entrevista" a aplicar. 
Decidimo-nos pela utilização do estudo de caso, considerando, no entanto, mais do que um caso na investigação, tendo realizado comparação multicasos o que nos permite a introdução do grupo de controle e a comparação entre os casos, com o objectivo de verificar se uma situação foi única ou, ao invés, se se podem encontrar semelhanças que permitam estabelecer relações de equiparação com outras situações que sofreram processos idênticos.

Na escolha do Objeto do Estudo optámos pela análise dos dois grupos de empresas fusionadas na área seguradora que se revelaram mais complexas em termos de dimensão e estrutura, atendendo, por fundamental à nossa investigação, ao factor Recursos Humanos. Por outro lado, também se demonstrou decisivo o papel que o fator antiguidade desempenhou nas empresas então fusionadas, especialmente na sua primeria fase, a nível de imagem, prioritariamente externa, tendo sido decisivo o facto de uma delas (Grupo A) ter a característica de conter a companhia mais antiga do sector. O segundo mais antigo, com características bastante idênticas, (Grupo B) foi escolhido por se poder fazer a comparação possível, com vista a encontrarmos referências de comparação - divergências ou convergências - relativamente ao primeiro, atendendo a que as circunstâncias base ao processo de fusão foram basicamente as mesmas, externa e internamente - pressões políticas nacionais e internacionais e situações económicas e financeiras instáveis e problemáticas.

O que nos levou à opção de pesquisa na atividade seguradora é o fato de ser uma das áreas mais significativas e representativas de procesos de fusão. Trata-se de uma situação bem conhecida em Portugal devido à evolução natural da realidade económica a nível internacional. Mais do que nunca tende-se para a unificação de grupos financeiros procedentes de diferentes áreas.

Mudanças económicas e sociais derivadas da Revolução de 74 tiveram consequências desastrosas que afetaram a atividade seguradora, em particular as companhias de seguros de pequena e média dimensão. Desde Maio de 1974 até Novembro do mesmo ano, tanto por influências externas como por reações a nível interno das empresas, foi surgindo uma situação negativa crescente que afetou empresários e empregados e que culminou numa série de medidas legislativas que impuseram a concentração por fusões e a reestruturação da atividade Seguradora imediatamente depois do resultado da Resolução de 78. Esta medida traduziu-se numa consequência direta das Nacionalizações ocorridas em Portugal, devido à mudança de regime político operado com a referida Revolução. Encontramos, assim, um conjunto de fatos derivados de toda uma conjuntura política vigente. Mas nesta nova etapa também não se traduziu mais positiva a forma como mudou o panorama empresarial, tendo afetado as estruturas internas, o funcionamento das empresas ao nível dos recursos humanos, a comunicação interna subjacente e suas consequências ao nível do clima e da cultura corporativa, na reestruturação provocada pelas fusões aí operadas.

É por isso que nos interessa analisar o papel que a comunicação interna desempenhou nas mudancas observadas, e como esta foi afetada. Demonstrar ainda, 
o grau em que, devido às mudanças introduzidas na estrutura das empresas, ela manteve eficácia perante a nova definição de funções e conseguiu fluidez ao longo das estruturas, entre organismos e hierarquias, com o fim de aproveitar ao máximo tais funções A hipótese de trabalho fundamental à investigação sugere que as fusões das empresas terão provocado disfunções a nível da comunicação interna que, por sua vez, se encontram relacionadas com procesos anómicos no seu público interno.

Daí deriva que a investigação apresenta como objetivo principal:

Caracterizar o funcionamento das empresas objeto de estudo a nível de recursos humanos e a sua comunicação interna interactiva, nos dois momentos definidos, antes e depois da fusão e, numa segunda fase, analisar o resultado das reestruturações em termos de equilíbrio do clima e coesão da cultura, assim como a efectiva participação da comunicação para conseguir o melhor resultado na Mudança.

O Campo de Observação, propriamente dito, é composto por elementos das duas unidades de observação - Grupo A e Grupo B. Assim, quer para um Grupo, quer para o outro, apresentamos um número de entrevistas proporcional a cada uma das subunidades relativamente ao total de trabalhadores de cada uma das duas novas empresas.

Em termos de técnica, o critério fundamental em que nos baseamos é a amostra mediante "Bola de Neve", no âmbito da qual aplicámos o inquérito sociológico.

Em abstracto, e assente em fundamentos teóricos debatidos, entende-se que, para estudos deste tipo, informações vindas de entre 18 a 20 por caso, desde que cumpram uma relativa proporcionalidade no âmbito da amostra definida em relação às empresas de origem, são o suficiente para a obtenção de dados informativos conclusivos. Isto independentemente da dimensão do universo que compõe o objecto de estudo. Segundo Albarello (Albarello et al, 1997,103) "nos estudos qualitativos não se coloca mesmo a questão da representatividade, no sentido estatístico do termo".

Ainda assim, tentou-se reunir uma amostra heterogénea composta de entrevistados homens e mulheres, com diferentes estratos etários no momento das fusões, em posições diversas na hierarquia das empresas, com habilitações a diversos níveis, e utilizou-se, com a relatividade possível, o critério da proporcionalidade entre o número de trabalhadores pertencentes a cada unidade que compôs as empresas fruto da fusão, de modo a obter-se a maior diversidade de informações desejável. Foi definido um total de 20 entrevistas para o Grupo A e de 18 entrevistas para o Grupo B. Devido às características particulares das situações que afectaram cada um dos entrevistados durante o processo de fusão, independentemente do seu perfil e categoria profissional, todos eles assumem uma mesma condição de informadores qualificados. 
Pensamos não nos poder alhear de um factor a ressalvar, que é o papel que os quadros intermédios - basicamente sub-chefes e chefes/coordenadores de serviço (consoante a designação assumida em cada uma das companhias) - detêm em termos de liderança. Já Schein afirmava em 1985 que "os leaders são os actores de maior importância na mudança de cultura" (Schein, in Thévenet, 1990, p. 178). O próprio Thévenet atribui ao leader uma responsabilidade de relevo ao afirmar que ele "não só vai dar uma visão da actividade e do projecto da nova empresa, mas deve também assegurar à sua volta a estabilidade da nova organização e criar uma estabilidade social e emocional" (Thévenet, 1990, p. 179). O seu papel torna-se, assim, fundamental neste tipo de situações, como no caso das fusões. E daí um pouco de privilégio da nossa parte relativamente à exploração das entrevistas dos indivíduos que se encontravam com cargos correspondentes no momento designado.

Em termos de Análise aplicámos a técnica da Análise de Conteúdo, através da Análise Categorial do Discurso, às Entrevistas Semi-estruturadas Presenciais - segundo guião (inquérito sociológico). Este tipo de Análise permite, numa segunda fase, uma Análise interpretativa, fundamental a um discurso aberto, consequente ao tipo de entrevista realizada, porque optámos para a obtenção da riqueza informativa pretendida e conseguida.

O tratamento das entrevistas seguiu os procedimientos da "Análise Temática do Discurso por Categorías", baseada nas dimensões de análise definida no Guião da Entrevista.

\section{ANÁLISIS Y DISCUSIÓN}

\subsection{Considerações a partir dos resultados da investigação}

Os resultados da investigação levam-nos a uma reflexão sobre a eficácia da comunicação para a eficácia dos processos de fusão e sua importância no âmbito das estratégias de gestão, problemática sobre a qual nos temos vindo a debater. Apresentamos aqui algumas das conclusões obtidas.

Desde a perspectiva dos recursos humanos, dos colaboradores da empresa, independentemente do nível em que se encontrem ou onde vão ser integrados, uma fusão requer tempo. Tempo de preparação. Tempo para pensar a reestruturação da empresa. É o ponto de partida. Preparação para pensar o modo como se pode levar a cabo sem atropelos. Tempo para dar tempo a que os colaboradores percebam e aceitem a mudança.

$\mathrm{Na}$ base da preparação está a comunicação. E a comunicação circula por toda a empresa, permitindo a integração dos colaboradores, a construção de um clima favorável, a mistura de culturas que suaviza o choque de um momento. O que poderá levar a que a formação de uma nova cultura, a coesão entre os trabalhadores e a criação de uma nova identidade institucional se desenvolvam mais facilmente. Mas tudo isto requer tempo. Tempo de adaptação, tempo de aceitação. Nada poderá ser 
imposto. O papel da comunicação interna de carácter informal A qualidade da informação é importante mas, em primeiro lugar prevalece a espontaneidade

- depois sim, há que pôr ordem, introduzindo a formalização necessária quando os ânimos já se encontram tranquilos, o que equivale a uma integração conseguida, um clima estável e um grau positivo de coesão entre os novos companheiros, dimensão mais difícil de alcançar devido ao conjunto de diferentes culturas que passam a conviver na nova empresa.

Nunca se deve pensar em imposições no início de um processo de fusão pois daí facilmente resultariam barreiras muito dificilmente intransponíveis que, naturalmente, conduziriam a um sentimento e atitude de rejeição, comportamentos inclusivamente descontrolados por parte dos mais inconformados. A este respeito, fazemos uma breve alusão às conclusões (online) a que chegou Eva Soares no âmbito das suas investigações, psicóloga e professora de recursos humanos, especialista brasileira nestas matérias, a que recorremos para os nossos próprios resultados:

Em um clima desse, os colaboradores de ambas as empresas ficam desnorteados. Não sabem se preocupam com a possível demissão, se planejam buscar uma nova ocupação no mercado, se preocupam em mostrar serviço para não ser demitido, se buscam mais informações sobre o processo pelo qual sua empresa está passando (e muitas vezes as informações não são acessíveis a todos os níveis hierárquicos, o que causa maior ansiedade).

A falta de comunicação num processo deste tipo pode ter consequências fisiológicas, resultantes tão somente do estado emocional. Vejamos:

E o que é mais grave nessa ansiedade toda, ainda lhe é cobrado resultado e discrição (...)Sem poder falar ou demonstrar o que está sentindo, tais colaboradores vão ficando cada vez mais "sufocados" apresentando sintomas diversos: dores de cabeça, dores lombares, dores no corpo inteiro, náuseas, diarreias, disfunções sexuais, etc. Todas sem causas biológicas ou fisiológicas mas sim com causa emocional.

A verdade, é que na maior parte dos casos, os sentimentos não se têm em conta e, como refere a autora: "o ser humano é e deve ser humano sempre. (...) e toda pessoa merece atenção especial, abertura, etc. para pelo menos falar do que a incomoda, daquilo que a angustia, daquilo que lhe causa ansiedade, independente se o ambiente é de trabalho."

Os colaboradores não podem ser tratados na nova empresa como peças isoladas num tabuleiro de xadrez. Há um contexto que não conhecem e que à partida, não têm intenção de conhecer. Se não são motivados, se não são ajudados nos seus primeiros passos, o jogo nunca começa. E é este o quadro ao qual se assiste, a estados de anomia 
que integram a nova estrutura, aos sintomas emocionais explicados atrás, assim como aos desvios nas relações interpessoais existentes na empresa. De tudo isso resulta a situação com que nos deparamos a maior parte das vezes: da fusão à confusão. Se, pelo contrário, se se conseguir motivá-los e dinamizá-los, eles poderão ser a chave para o êxito de uma mudança.

Partindo desta perspectiva aludimos a um caso real de pleno êxito estudado e apresentado por Carlos Parente (online) que começa por dizer-nos que "com a participação activa da comunidade interna é possivel promover processos de integração entre instituições diferentes, respeitando as diversidades culturais". Para o autor, o êxito de uma fusão parte da própria mobilização do público interno. $\mathrm{Na}$ situação que agora referimos diz-nos que a "organização decidiu estabelecer um processo de integração gradual e baseado em sólidos valores corporativos". Sucederam-se acções em que os trabalhadores de ambas as empresas fusionadas foram os protagonistas dos eventos, situações onde reinava a emoção, a confraternização e a energia positiva. Como diz Parente "é fundamental estabelecer um processo de integração gradual e baseado em sólidos valores corporativos [institucionais].

Não querendo estendermo-nos, atendendo a que as fusões investigadas por nós tiveram lugar em 1980, num campo de investigação então ainda não explorado dentro desta área de conhecimento, será abusiva a exigência paralela a uniões que têm lugar já no século XXI e com países em fases de desenvolvimento muito diferentes neste campo da ciência, como Brasil e Portugal.

Numa posição, talvez um pouco de defesa, podemo-nos colocar a par da investigadora Maria João Centeno a qual, apesar de tudo, nos traça uma visão mais moderna sobre a mudança. Uma perspectiva dinâmica, segundo ela às vezes demasiado, que a autora prevê, à partida, difícil de controlar. Ainda que num contexto diferente diz-nos precisamente que "o ritmo vertiginoso da mudança é cada vez mais difícil de controlar", concluindo o seu raciocínio da seguinte maneira: "...esta situação [as consequências] torna difícil montar canais de comunicação permanentes $e$ reacções que conduzam a uma verdadeira compreensão e mudança recíprocos" (online).

A verdade, apesar de tudo, é que esta é uma realidade por nós constatada perante o que observámos: quando existe uma preocupação das empresas em unir-se pouco a pouco, tentando que se mantenham os fluxos de comunicação, abrindo novos canais perante as necessidades emergentes e desenhando uma estrutura adequada ou, em simultâneo, deixando que a comunicação flua informalmente num primeiro momento 'ad libitum', para colmatar as lacunas que se apresentam, é a forma de conseguir uma integração mais fácil e obter um clima mais estável dentro da nova empresa. E quando chega o momento da fusão efectiva, já está quase tudo feito. Pode dizer-se que está criada uma nova identidade institucional. Formaliza-se e inaugurase a empresa 


\section{CONCLUSIONES}

Muitas vezes as mudanças são implantadas sem que os responsáveis nas empresas tenham as informações necessárias sobre o processo. Os agentes da mudança são ultrapassados por situações que não dominam e reproduzem um discurso, sem sequer possuírem, na maioria das vezes, a identidade do autor. Alguém prepara o texto das mudanças para outros desencadearem tal processo. A partir da interpretação do agente de mudanças (aquele que torna as mudanças efectivas), o discurso original vai perder a sua originalidade, e com ela os seus fundamentos. Este discurso será apresentado através de várias lentes, interpretado através de outras lentes, vai ter diferentes leituras, dará origem a poucas vozes mas muitos silêncios.

Perante isso, o profissional de Comunicação deve avaliar os resultados da recepção da nova estrutura organizacional com tudo o que ela encerra, tendo em vista as diversas interpretações por parte do público receptor.

Mediante todas as transformações vividas, hoje, a verdade deixa de ser uma condição objectiva, pois torna-se numa questão de credibilidade aceite. Nessa medida o profissional de Comunicação deverá identificar a credibilidade daqueles que sustentam o discurso organizacional com que trabalha. Caso contrário, o seu trabalho de Comunicação enfraquece, pois não terá a recepção e o apoio dos públicos envolvidos.

Numa situação de mudança há que haver uma desconstrução e reconstrução dos discursos organizacionais com vista à convivência das distintas culturas, para uma melhoria da vida dos públicos dentro da organização.

O profissional de Comunicação, ao lidar com o discurso das mudanças, passa a gerir tantos antagonismos que a integração e a coesão tornam-se conceitos sem algum

significado. E o seu papel tem que ir, obrigatoriamente, mais longe. Tem que aprender a combinar diferenças e antagonismos para adequar o seu discurso, reconhecendo a impossibilidade na estratégica da coesão e da integração no recente convívio do pluralismo e do individualismo, agora muito mais pautados por critérios de flexibilidade, efemeridade, despadronização.

O seu campo de actuação vai encontrar culturas organizacionais caracterizadas pela fluidez, incerteza, volatilidade, competências, talentos, fragmentação, combinação da diversidade, opondo-se às das tradicionais, anteriores às mudanças que caracterizámos. A nova organização vai ser definida através de uma heterogeneidade, com objectivos multidimensionais, que congrega simultaneamente elementos de integração, de diferenciação, de conflito, de poder e que deve lidar com a incerteza e com a construção de novos valores, crenças, competências e, sobretudo, com a criação de novos discursos e novas credibilidades.

Mas compete-nos terminar com uma mensagem de esperança. Esperança 
fundamentada Cientificamente.

Cabe à Comunicação Interna e, concretizando um pouco, muito às Relações Públicas enquanto função estratégica na Comunicação Integrada, no âmbito da estratégia Global da Gestão da Empresa, restabelecer o equilíbrio perdido em situações de mudança.

Posicionadas privilegiadamente, têm responsabilidade de conhecer a cultura da empresa nas suas distintas nuances; próximas da Administração, melhor do que ninguém para aportar todas as sensibilidades obtidas na empresa até junto da Administração. Tendo os profissionais de R.P., por sua formação, preparação académica em áreas de gestão e de recursos humanos, encontram-se aptos para dar assessoria ao topo empresarial no sentido da gestão dos conflitos, das incertezas, das mais diversas situações problemáticas sentidas em campo, no dia a dia da organização.

Já assim, com uma missão integradora a nível interno da organização, acreditamos que, com a intervenção dos profissionais, assentes nas estratégias da Comunicação Integrada, de acordo com os objectivos definidos superiormente, se consiga uma convivência de distintas culturas, obtendo-se um clima interno estável dentro da empresa.

Mas a função das R.P assume-se como estratégica de Comunicação. Significa isto que, hoje, a sua acção não é mais vista como pontual, mas sim continuada. Tem objectivos e, para isso, actua com base num Plano, com vista ao cumprimento desses objectivos.

Relembrando um pouco do caso apresentado, muito sinteticamente, verifica-se que no Grupo B se conseguiu uma integração facilitada devido à eficácia da Comunicação. Nada foi imposto porque houve tempo para as mudanças acontecerem por si mesmas e a vontade dos colaboradores participarem na nova estrutura demonstrou-se bastante significativa.

Experiências desta natureza traduzem-se num alerta para situações bem actuais com características semelhantes. Casos de Mudança em empresas que impliquem a nova convivência de grupos de origem distinta, tão na moda, a nível nacional e mesmo internacional.

Em termos finais, o que deixamos bem patente é a chave do que hoje se apresenta fundamental para fazer a diferença entre uma Mudança numa organização, que poderá ser uma fusão, uma aquisição, uma aglutinação... Processos tão na ordem do dia, em economias onde as empresas de pequeno porte já não encontram futuro. E essa chave para a Mudança, que indirectamente nos foi aportada com a investigação que realizámos, traduz-se num único conceito, que muitas consequências vem suavizar: Planeamento. 


\section{REFERENCIAS}

Albarello, L.; Digneffe, F.; Hiernaux \& J.-P. (1997). Práticas e Métodos de Investigação em Ciências Sociais. (Trad. L. Baptista). Lisboa: Colecção Trajectos

Almeida, V. (2000).A Comunicação Interna na Empresa, Lisboa: Praxis.

Bériot, D. (1997). Mudança na empresa - uma abordagem sistémica - Do microscópio ao macroscópio. Lisboa: Colecção Sociedade e Organização.

Bernoux, P. (1985). La Sociologie des Organizations. Paris: ed. du Seuil,.

Cunha, M. P.; Rego, A.; Cunha, R. C. \& Cardoso, C. C. (2003). Manual de Comportamanto Organizacional e Gestão. Lisboa: RH Editora.

Ferreira, J. M. Carvalho; Abreu, J.N. P. \& N.de; Caetano, A. (1996). Psicosociologia das Organizações. Portugal: McGraw-Hill.

Goffman, E. (1985). Manipulação do Eu na Vida Quotidiana. Lisboa: Ed. Vozes.

Jablin, F. M., Putman; L., Roberts, K. H. \& Porter, L. W. (1987). Handbook of Organizational Communication: An Interdisciplinary Perspective. CA, Sage: Newbury Park.

Lakatos, E. (1987). Sociologia Geral, Atlas. Paulo.pp. 318-319.

Lopes, A. \& Reto, L. (1990). Identidade da Empresa e Gestão pela Cultura. Lisboa: Colecção Economia e Negócios.

Martins, V. M.B (2004). Evolución de la Satisfacción y Comunicación Interna. Tese de Doutoramento, Universidad Complutense de Madrid, España.

Ouchi, W. (1985). Revue de Litterature sur la Culture de l'Entreprise, UCLA.

Peters, T. Waterman, Jr., \& Robert H. (1987): In Search of Excelence (Na Senda da Excelência). Lisboa: Pub. D. Quixote.

Sainsaulieu, R. (1977). L'identité au travail. Paris: Fondation Nationale des Sciences Polítiques.

Schein, E. H. (1985).Organizational Culture and Leadership, Jossey-Bass

Schumacher, E.F.( 1978). Small is Beautiful - une societé à la mesure de lhome. Paris: Ed. du seuil. 
Teixeira, S. (1998).Gestão das Organizações. Portugal: McGraw Hill

Thévenet, M. (1990). Cultura de Empresa, auditoria e mudança. Paris: Monitor (Original em francés, 1986)

\section{Anabela Ferreira Félix-Mateus}

Investigadora de pós-doutoramento em Ciências da Comunicação no Departamento de Relações Públicas, Propaganda e Turismo da Escola de Comunicação e Artes da USP e no Departamento de Letras, Artes e Comunicação do Centro de Estudos Linguísticos da UTAD, como bolseira de Pós-doutoramento da FCT (Fundação para a Ciência e Tecnologia), patrocinada por Fundos Europeus. Prossegue projeto de parceria entre Portugal e Brasil intitulado 